\title{
Transforming thought through reflective experiential learning
}

\begin{abstract}
Through the it is not a specific process but one of many approaches process of situational reflection, this paper examines how reflection on experience can be used as a tool for improving teacher practice. Examinations at the end of a university semester revealed that educators-beginners have become resilient to applying reflective thought to practice due to a lack of direction or specific knowledge about the process of reflection. Adapting Kolb's model of experiential learning to transformational and reflective learning processes, this research suggests that reflection needs to be outlined and defined for it (for what?) Kolb's model of experiential learning (perhaps "for its being purposefully and meaningfully applied to learning"?) to purposefully and meaningfully apply to learning. In essence, this study examines how reflective processes enhance experiential learning, identifies the role of reflection in learning and instruction, and offers recommendations as to how reflection can be incorporated into teacher practice.
\end{abstract}

Keywords: reflective practice, experiential learning, transformative learning, reflection-in-action, action research, educational practice, critical reflection
Volume 2 Issue 2 - 2018

\author{
Linda Rappel \\ University of Calgary, Canada
}

Correspondence: Linda Rappel, University of Calgary, Tel (403) 246-8I79, Email Canadalrappel@ucalgary.ca

Received: January 04, 2018 | Published: April 10, 2018

\section{Transforming thought through reflective experiential learning}

Though there are documented approaches to teaching and learning that reflect specific school administration and governmental objectives, within these boundaries there is room for educators to make connections between institutional and instructional objectives. As a professional practice, teaching allows educators to make decisions about individual approaches to instruction based on personal preference, ideas, ability and background in order to make reasonable and sensible instructional choices within specific learning contexts. For many, reflection is key to unlocking these variables of instruction and establishing solutions that address the complexities of teaching and learning. Through a process of action research, this paper examines how using reflection on experience as a tool for learning can enhance educator professional development and improve teacher practice.

\section{Context}

One of the learning tasks assigned to a group of beginning educators earlier this year involved reflecting on learning as part of preparation for upcoming teacher practice. Embarking on reflective assignments, students complained that they had done too much reflection and not enough learning about specific instructional strategies.

In reality, hesitation to use reflective strategies to improve practice might have stemmed from the fact that educators- beginners had not been allowed to integrate reflection into their overall learning process. Instead, reflection was viewed on as a stand-alone activity rather than an application of theory to practice as a procedural part of learning. In effect, reactions to this assignment suggested that there were obstacles blocking the ability to perceive learning as a process of adjustment, assessment and readjustment. Though it was evident that these beginning educators knew It is more than knowing about; it is understanding or developing an understanding about how these processes apply to learning. About processes of inquiry, they appeared unprepared to accept a format of learning that left room for the paradox of possibility and uncertainty.

Essentially the primary goal of the assignment was to provide an opportunity for creative expression and collaborative exploration by criticising the previous instructional experiences in a group setting. Original version: In essence, the primary goal of the assignment was to provide an opportunity for creative expression and collaborative exploration by critiquing previous instructional experiences in a group setting. Author comment: The whole point of the article is to make the distinction between criticising and critiquing. If you want me change this, you've obviously missed a huge perspective of this manuscript and therefore either I have not expressed myself clearly or you have not understood my point and neither will other readers.

Still, many educators-beginners this is not it; they are beginning or pre-service educators not educators - beginners continued to be preoccupied with the final result of their own efforts rather than focussing on critical and reflective aspects of learning. As a result, these learners/educators were hesitant to accept ambiguity and the possibility of reframing perspectives through discussion. Coming from structured learning environments that had likely led to academia, beginning educators were uncertain about how a process of collaborative inquiry could in fact be an effective way to learn. More specifically, these educators were unsure about how to develop attitudes of group cohesion that permitted reflection. Instead, they seemed stuck in individualistic, competitive paradigms that left little space for creativity and collaborative reflection.

\section{Aims of research}

The primary aim of this study was to determine how elements of reflection and collaboration help assess experience and establish a reflective practice. Using a specific context of beginning educators as a basis for exploration, this research examined how critical reflection on experience can be used as a tool to improve teacher practice through 
applying a framework of experiential and transformative learning to educational environments.

\section{Research question}

The goal of this study was to address the following research question: How can approaches to reflection are enhanced through applying a framework of experiential and transformative learning to situations of educational practice?

\section{Theoretical framework}

Educators and learners alike may take reflection for granted as a natural and reflexive activity. Still, much like many learning processes, reflection on experience is a learned skill that can increase ability to make meaning and generate individual and collective understanding in educational situations and professional practice. ${ }^{1}$ In effect, the ability to reflect on experience as part of a professional approach to learning can be described as reflective practice. Identifying the connection of reflection on experience to professional practice, Higgins ${ }^{2}$ outlines a definition of reflective practice in the following:

The term reflective practice conveys meanings that range from the questioning of presuppositions and assumptions, through to more explicit engagement in the process of critical and creative thinking in order to make connections between experience and learning in practice and practical action. The practices of reflection suggest a method of inquiry which is characterised by engagement, pondering alternatives, drawing inferences and taking diverse perspectives, especially in situations which are complex and novel, calling for situational awareness and understanding. (p. 583)

\section{Viewing transformation through reflection on experience}

Thorsen \& DeVore ${ }^{3}$ suggest that reflective practice is an integral part "of evaluating one's own teaching performance and preparation, learner outcomes, and the ability to promote learning, social interaction, and self-actualization in students" (p. 89). As an approach to educational practice, reflection has been noted as a way of drawing on previous experience to gain understanding of new perspectives and transform ways of thinking, particularly for adult learners and practitioners. ${ }^{4-6}$

Describing opportunities for reflective practice, Schön ${ }^{6}$ makes the distinction between reflection-on-action, which suggests a review process conducted at significant points in time, and reflection-inaction, which is an ability to solve problems that occur through active awareness. It is the second function of reflection-in-action that is most often related to reflective practice and therefore significant to this study. Outlining the process of reflection-in-action, Russell ${ }^{1}$ notes three important steps in this process, which are detailed as follows:

i. A puzzling or surprising event during teaching might stimulate 'reframing,' recognizing a new way of perceiving or thinking about the professional situation of practice;

ii. The new perspective might stimulate a novel course of action; and

iii. Actually carrying out the novel course of action might provide evidence for deciding if the new perspective and associated new actions deserved to be included in future professional practice. ${ }^{1}$
Related to reflective practice, experiential learning involves a shift in cognitive structures that results in a reframing of experiences and consequently a transformation of attitudes and/or behaviours. ${ }^{7}$ According to the shift in cognitive thinking can impact teacher effectiveness through incorporating educator background to theory from an experiential perspective. Thorsen \& DeVore ${ }^{3}$ suggest that this approach to improving professional practice is based on the idea that self-discovery is a key part of learning and that learning and experience work together to support collaborative, active and transformative learning processes. In a sense, the combination of experiential learning to reflective practice creates a learning cycle where learners have the opportunity to touch on all aspects of learning: "experiencing, reflecting, thinking and acting in a recursive process". 8

As highlighted through both experiential ${ }^{7}$ and transformative ${ }^{9}$ learning, embracing experience as a reflective practice holds possibilities for personal and professional growth while incorporating new information into overall cognition. This reinforces Johnson \& Johnson's ${ }^{10}$ point that information alone cannot serve to change attitudes (p. 51). Rather, there is connection established to Freire's ${ }^{11}$ notion of praxis where positionality is enacted and reinforced through practice.

The goal of reflective practice is to ensure an integrated approach to understanding where reflection plays a role in transforming perspectives through the cycle of experiential learning (Figure 1). This pragmatic view of educational practice reinforces Dewey's ${ }^{4}$ earlier notion that purposeful reflection is a complex process involving openness to change in order to assess experience based on current knowledge and skill. The diagrams below outline the transfer occurring from the experiential cycle of learning to a process of reflection:

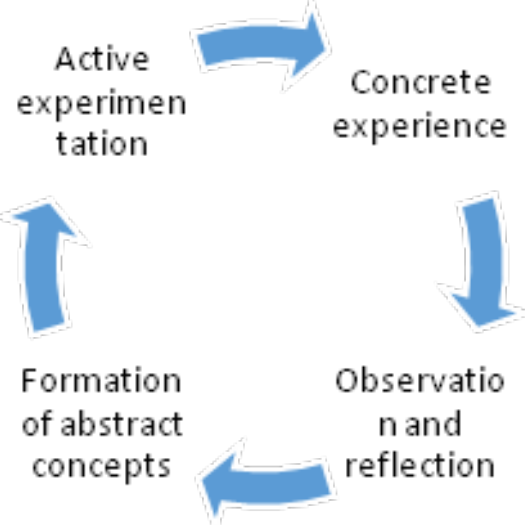

Figure I Kolb's (I984) cycle of experiential learning.

\section{Methodology}

This research examines instructional and learning activities of not fully fledged beginning educators as described previously, which can simply be restated (Figure 2). Teachers involved in reflective practice through action research. Since action research offers a way to inquire into specific situations of professional practice and provide evaluative interpretations of actions taken, this methodology establishes a good foundation to explore applications of knowledge to practice and investigate avenues for improvement in developing a reflective 
teacher practice. ${ }^{12}$ In particular, McNiff ${ }^{13}$ suggests that this style of inquiry offers the opportunity to transform "living theories" into practice by developing ways of understanding how theory influences behaviour through a cycle of action, observation and reflection (p. 15). Using a self-study approach to action research, ${ }^{14}$ this research follows a specific instructional experience that occurred over the course of one semester to examine the effectiveness of reflecting on experience as a primary tool for improvement of educational practice.

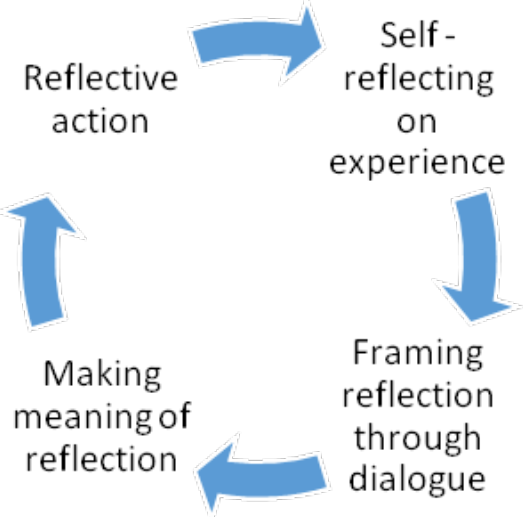

Figure 2 Adaptation of cycle to focus on reflection.

\section{Literature}

To complete this study, the information gathered from the literature was discussed through the lens of experiential and transformative learning as applied to reflection on practice. The data was explored by first outlining barriers to reflective learning and then by reviewing how educators are able to move through a cycle of learning using a reflective process of critique and collaboration.

\section{Recognizing barriers to reflective learning}

One of the difficulties in supporting learning through reflection is the tension involved in offering innovative approaches to learning while attending to diverse learner needs that exist in current educational environments. In a critique of reflective practice, Davis ${ }^{15}$ outlines how the need to provide a "wider access" to learning places an emphasis on uniformity to allow for grounding of collective knowledge (p. 245). For her, this comes at the risk of neglecting the development of more creative and intuitive forms of understanding that are linked to reflection.

In reality, the endeavor to establish equitable platforms for learning reinforces a "groupthink" style of problem solving that discounts a diversity of perspectives that could be addressed in and applied to educational practice. ${ }^{10}$ Offering wider access for learning is a great way to ensure that learners attain similar bases of information within a particular area of study. However, this same practice can reduce creative approaches to teaching and learning that involve reflection, examination of experience and collaboration. For educators, these are necessary tools for developing a teacher practices based on critique and examination of experience.

Noting the desire for beginning educators to conform to normative educational standards and be accepted within the educational community of practice, the tendency to adopt groupthink styles of critiquing practice is strong. As a result, there may be a hesitancy to fully participate in reflective activities as part of learning and inquiry. This reluctance to participate in reflection may stem from barriers as outlined below:

1. An inability to deal with stressful situations by recognizing perspective and realities of learning.

2. An inability to develop a sense of group belonging and security in order to identify and define meaningful experiences related to the learning process.

3. A lack of willingness to devote time to consider feedback and reflect on experience.

4. An ontology that does not readily accept and incorporate meaningful feedback into revised action and beliefs.

Contrary to attaining unified perception that reflects a groupthink approach to educational practice, the goal of reflection is to acquire personal and professional knowledge in order to creatively forge a connection of theory and practice. As Thorsen \& DeVore ${ }^{3}$ indicate, reflective practices are complex processes that involve rigorous and disciplined approaches of systemic inquiry in order to invoke a deep understanding of issues that are a part of educational practice. To participate in this activity, learners need to have an ability to think critically about experiences, time to consider individual aspects of practice, and a sense of maturity in order to participate in this type of collaborative inquiry.

\section{Moving through the cycle of reflection}

Combining theories of experiential and transformative learning, educators are able to make connections from theory to practice by moving through a cycle of reflection of experience. The stages within this process address barriers outlined by Davis ${ }^{15}$ and suggest ways in which an intentional application of a cycle of reflection relate to learning and critique of educational practice.

\section{Self-reflection of experience}

Russell ${ }^{1}$ suggests that taking the first step of reflection involves developing an active awareness of the connections between personal elements and professional practice. These initial stages of reflective exploration shed light on the lived realities of individuals and as a result may uncover vulnerability in learners and educators. While this type of recognition contributes to the identification of behaviours and experiences that allows educators to develop increased awareness about themselves and their work, it may force individuals to confront uncomfortable realities.

Recognition of strengths and weaknesses can be in fact be colored by feelings of inadequacy that stem from perceived failures. In a discussion on shame, Walker ${ }^{16}$ notes how a reflective process can reveal buried emotions that arise from lost opportunities, unreached goals, or unachieved expectations. These deeply felt emotions have the effect of increasing stress and may therefore result in an unwillingness to disclose relevant information about the connection of self to learning, exploration of teaching experiences and examination of teacher practice.

Walker ${ }^{16} \&$ Thorpe $^{17}$ both recognize that uncovered emotion may lead to questioning one's value, worth and ability. As Thorpe ${ }^{17}$ explains, feelings of insecurity and anxiety can accompany reflection. To this end, she suggests that "reflective thinking requires a trusting 
relationship if one is to write about individual thoughts, feelings, and experiences honestly; adequate time to consider ideas critically; active participation; involvement of self; and commitment" (p. 328).

Because of the connection of the realm of the private to the public in educational practice, the capacity to self-acknowledge and selfreveal is essential for educators, ${ }^{18}$ to support this claim, Palmer notes that it is in fact through exploring identity and integrity that educators are able to create effective instructional situations. However, embarking on self-recognition and self-assessment is dependent on the ability to develop the awareness necessary to perceive realities within instructional situations. This includes the capacity to identify difficulties, clearly assess situations, and take risks to move forward into the learning process with confidence and stability. ${ }^{18,19}$

\section{Framing reflection through dialogue}

According to Russell, ${ }^{1}$ reflection-in-action can be taught "explicitly, directly, thoughtfully and patiently" through developmental practice (p. 203). This type of narrative inquiry through dialogue relies on a sense of group cohesion and belonging in order for it to be a worthwhile venture. Though reflecting on experience is primarily viewed as an individual activity, much can be gained by undergoing reflection through collective discourse.

According to Higgins, ${ }^{2}$ the practice of critical dialogue involves the examination of "presuppositions and assumptions through explicit engagement in the process of critical and creative thinking in order to make connections between experience and learning in practice and practical action" (p. 583). In other words, for reflection on practice to be meaningful, it must combine an ability to critically review and revise ideas and attitudes through the examination of past behaviour and action. In essence, the ability to reflect on process and self-present in group settings requires a balanced sense of self, a mature outlook, a sense of belonging and group cohesion in addition to attaining a certain level of comfort in exploring experiences for the purposes of learning and reflection. ${ }^{16,17}$

Freire $^{20}$ recognizes how education involves taking risks through being open to new opinions, thoughts and insights that are revealed through learning. According to Freire, ${ }^{19}$ a dialogical approach to learning can offer significant opportunities to rethink and review approaches to educational practice. Once individuals achieve the confidence or maturity to participate in a dialogical process of learning, it can become a meaningful way to evaluate actions that are taken as part of educational practice.

Creating an educational environment with the intention of offering a platform for critique and analysis relies on establishing a sense of belonging in group situations. This can be achieved through the development of respectful and trusting attitudes..$^{10,17,16,21}$ One of the ways to ensure group cohesion is to work towards the establishment of cooperative rather than competitive attitudes in learning and group participation. $^{10}$

\section{Recognizing new perspectives that influence attitudes and behaviour}

Reflection involves numerous cognitive processes such as "thinking, communicating, revising, and refining of observations and events". ${ }^{3}$ Most often reflective thinking takes time and may include periods of assessment on feedback before insight into situations and transformation of beliefs, values and attitudes can be achieved. ${ }^{3,9}$
During this time, learners experience some disequilibrium as they encounter new ways of exploring issues and situations. ${ }^{3}$

Moving past tensions involved in re-evaluating behaviour is a significant step in reframing thoughts that precede behavioural shifts and result in discovering alternative ways of knowing. Cameron ${ }^{22}$ comments on these actions as offering an "outsider view" that invokes insight to reassess and replace previously held assumptions. In reviewing past experiences and habitual thought, individuals are able to see beyond conventionality, basing knowledge on a lived context that generates theories in regards to learning. ${ }^{22}$

Holding an "outsider view" of educational processes offers the opportunity for educators to take a renewed look at teacher practices. Additionally, holding a more objective view of practice allows educators to better position their own views and provides a basis for recognition of cultural differences and diversity that enter into learning environments. ${ }^{3}$ In fact, critically evaluating experience offers the possibility for educators to base practice and knowledge on practical experience rather than historical action, which may be neither contextualized nor relevant to specific educational situations.

\section{Reframing experiences through revised action}

Gnawali $^{23}$ claims that "a major aim of education is to help learners to understand themselves as persons and as individuals" ( $p$. 69). Palmer ${ }^{18}$ describes this well by indicating that learning is most effective when there is a connection of the inner lives of educators to those of learners. Accomplishing this goal involves taking a realistic view of educational situations and processes. In essence, developing awareness based on reflection-in-action allows practitioners to take a proactive approach to improving professional practice by evaluating situations as they occur. ${ }^{24}$

According to Thoresen $\&$ DeVore ${ }^{3}$ educators today use reflection to inform teacher practice for a number of reasons: the first is to adjust methods to suit the learning context; the second is to improve overall effectiveness and learner success; and the third is to reflect on how outside social and political issues enter into and influence learning environments. Developing a reflective practice that includes critique of experience is achieved by linking learning to action that acknowledges distinct motivations and purposes for making decisions about action. ${ }^{2}$ This activity is related to Freire' ${ }^{11}$ conception of praxis that outlines the importance of consequent action that results from increased or renewed awareness.

Preventing a view of education that is ritualized and embedded in unconscious behaviours, reflective practice offers a way of making sense of and revising actions that are a part everyday work as an educator. ${ }^{23}$ In essence, this type of reflection on experience allows educators to make connections between tacit and explicit knowledge in a quest to gain insight into actions, recognize purpose, and generate a greater awareness of the impact educators have within the learning environment. This brings teacher education past the notion of training onto an educational path that makes assessments through continued attention to an examination of actions taken within educational settings. ${ }^{23}$

\section{Findings}

Russell ${ }^{1}$ notes how discussions about reflective practice tend to centre on the value of reflection rather than reviewing elements of reflection as a specific educational activity. Essentially, difficulties 
inherent in applying reflection to practice as outlined by Russell mirror experiences described in this study. In general, beginning educators expressed hesitation about exploring aspects of educational practice due to inexperience or anxiety about revealing aspects of personal or professional lives within a group of peers.

In reality, embarking on active reflection may be more complex than it initially appears. Russell ${ }^{1}$ contends that fostering critical dialogue that increases self-awareness involves more "than telling people to reflect and then simply hoping for the best" (p. 203). What was discovered in this and in other studies ${ }^{2,25}$ is that active and critical reflection on experience presents the challenge of engaging independently and collectively to discover solutions to problems and situations that arise in professional practice.

One of the difficulties encountered in evaluating experience through reflective practice is that educators may not have developed enough trust in them or in group settings to divulge personal information. In this study, it was evident that although beginning educators were willing to embark on reflection as a way to improve practice, many were hesitant to pursue a critical examination of behaviour or actions for fear of divulging weaknesses or through a lack of knowledge about how to proceed with an in-depth process of self-examination.

It is clear that one drawback of applying reflection to experience as a way to improve practice was that this activity was met with increased anxiety due to a strong desire for uniformity and the need to be accepted within a community of educational practice. In other words, the need to "do it right" may override the value of self-critique and evaluation. In this study, there was resistance to the idea of viewing learning and teaching as encompassing points of unpredictability. This reflects the importance educators place on following norms of practice and therefore maintaining a secure approach to evaluating practice.

To support this view, there has been recognition of the fact that a lack of distinction between observation and assessment is a common issue in encouraging reflection on experience as way to improve teacher practice ${ }^{26}$ Because the two processes of formal and formative evaluation may be blurred, there is a fear of judgment that may inhibit an honest critique of practice. This reinforces a traditional view about the purposes of classroom observation being solely a means of uncovering problems and discovering what is wrong rather than offering opportunities to carefully review and improve practice. ${ }^{26}$

Educators who rely on reflection to support and improve their practice recognize that a certain level of uncertainty is a necessary part of educational work. In reality, using reflection as a viable method of critiquing educational practice requires patience and perseverance. ${ }^{15}$ As teaching itself, reflection on practice is not a step by step procedure that follows a prescriptive pattern; rather, it offers deep, cyclical and experiential learning that requires effort and the ability to view knowledge not as a commodity but as a socially constructed dynamic that can be applied to practical situations. ${ }^{17}$ It is therefore essential from the outset to encourage educators that a vested interest in procedure is as much a requirement as attention paid to learning content and results in developing this approach to improving educational practice.

Recognizing spontaneous and intuitive aspects of teaching requires educators to be able to reflect on action and self-assess through experiential information gathered from instruction. Viewing education as a "form of creative expression-characterized as multimodal, nonlinear, and multidimensional" (p. 63), Cole \& Knowles ${ }^{26}$ encourage educators to review educational practices through recognizing how personal elements merge with professional demands to influence educator views and perceptions. Palmer ${ }^{18}$ recognizes how the inclusion of personal elements into professional practice through intentional reflection opens up avenues for establishing effective educational practices.

Acknowledging how autobiographical aspects enter into teaching practice reinforces the need for reflection-in-action as an integral part of improving educational practice. ${ }^{26}$ In this way, the focus remains on deconstructing experiences through inquiry in order to foster understanding in and amongst educators. Through recognizing the importance of exchanging knowledge, information and diverse understandings about the practice of teaching, educators are able to accept who they are as educators and how they operate in specific situations. ${ }^{18,19,26}$ This knowledge can only serve to improve educator practice. ${ }^{27-30}$

\section{Conclusion}

According to Dewey, ${ }^{4}$ the benefits of developing a reflective practice in education binds educators to duty through fostering enthusiasm and increased awareness along with open-minded attitudes in regards to diverse applications of theory to practice. In a sense, ${ }^{27}$ developing a reflective stance in educational practice invites educators to engage courageously and creatively in improving practice using insight gained from practical experience,${ }^{16}$ for many, reflection is key to exploring elements of instruction and establishing solutions to better address complexities of educational practice.

\section{Acknowledgment}

None.

\section{Conflict of interest}

None.

\section{References}

1. Russell T. Can reflective practice be taught? Reflective Practice. 2005;6(2):199-204.

2. Higgins D. Why reflect? Recognizing the link between learning and reflection. Reflective Practice. 2011:12(5):583-584.

3. Thorsen CA, DeVore S. Analyzing reflection on/for action: A new approach. Reflective Practice. 2013;14(1):88-103.

4. Dewey J. How we think: A restatement of the relation of reflective thinking to the educative process. Boston: Heath; 1933.

5. Mezirow J. Transformative learning: Theory to practice. New Directions for Adult and Continuing Education. 1997;74:5-12.

6. Schön DA. The reflective practitioner: how professionals think in action. New York: Basic Books; 1983.

7. Kolb DA. Experiential learning: Experience as the source of learning and development. New Jersey: Prentice-Hall; 1984. 256 p.

8. Kolb AY, Kolb DA. Learning Styles and Learning Spaces: Enhancing. Academy of Management Learning \& Education. 2005;4(2):193-212.

9. Mezirow J. Transformative dimensions of adult learning. San Francisco: Jossey-Bass; 1991. $247 \mathrm{p}$. 
10. Johnson DW, Johnson FP. Joining together: Group theory and group skills. 11th ed. Boston: Pearson; 2017.

11. Freire P. Education for critical consciousness. New York: Continuum, 1974.

12. Creswell JW. Research design: Qualitative, quantitative and mixed methods approach. 4th ed. Thousand Oaks, CA: Sage; 2014.

13. McNiff J. What is action research? In: McNiff J, Whitehead J, editors. All you need to know about action research. 2nd ed. New York: Sage; 2011.

14. Reason J, Bradbury J. The Sage Handbook of Action Research: Participative Inquiry and Practice. 2nd ed. London: Sage; 2008.

15. Davis M. Barriers to reflective practice. Active Learning in Higher Education. 2003;4(3):243-255.

16. Walker J. Explorations of shame in adult learning and education. Paper presented at the Annual Conference of the Canadian Association for the Study of Adult Education Annual Conference, Calgary, Alberta; 2016.

17. Thorpe K. Reflective learning journals: From concept to practice. Reflective practice. 2004;5(3):327-343.

18. Palmer PJ. The courage to teach: Exploring the inner landscape of a teacher 's life. San Francisco: Jossey-Bass; 1998. 199 p.

19. Brookfield S. The skillful teacher. San Francisco: Jossey-Bass; 2006.

20. Freire P. Pedagogy of indignation. Boulder, CO: Paradigm; 2004. 129 p.

21. Jensen K, Bennett L. Enhancing teaching and learning through dialogue: a student and staff partnership model. International Journal for Academic Development. 2016;21(1):41-53.
22. Cameron P. Learning with a curve: Young women's depression as transformative learning. Paper presented at the Annual Conference of the Canadian Association for the Study of Adult Education Annual Conference, St. Catherine's, Ont; 2014. 23 p.

23. Gnawali L. Teacher development through reflective practice. Journal of Education and Research. 2008;1(1):69-71.

24. Furman G. Social justice leadership as praxis: Developing capacities through preparation programs. Education Administration Quarterly. 2012;48(2):191-229.

25. Lyle E. From method to methodology: narrative as a way of knowing for adult learners. The Canadian Journal for the Study of Adult Education. 2013;24(2):17-34.

26. Cole AL, Knowles JG. Researching Teaching. Halifax, NS: Backalong Books; 2008. 220p.

27. Seng TW. Practicum student teachers' reflectivity, practicum performance and clinical supervision. In: AARE 2001 Conference Papers. 2001.

28. Schein EH. On dialogue, culture, and organizational learning. Reflections. 2003;4(4):27-38.

29. Experiential Learning in Higher Education. Academy of Management Learning \& Education. 4(2):193-212.

30. Lindeman EC. The meaning of adult education. New York: Harvest House; 1961. 